\title{
Frequency of Accelerated Bacillus Calmette-Guerin Response in Bacillus Calmette-Guerin Vaccinated Children
}

\author{
MUHAMMAD IRFAN ${ }^{1}$, SYED USAMA MASOOD ${ }^{2}$, TALHA LAIQUE ${ }^{3}$ \\ ${ }^{1}$ Department of Medicine, DHQ Hospital, Lodhran -Pakistan \\ ${ }^{2}$ Department of Pediatric Nephrology, Children Hospital and Institute of Child Health, Multan-Pakistan \\ ${ }^{3}$ Department of Pharmacology, Allama lqbal Medical College, Lahore-Pakistan \\ Correspondence to Dr. Talha Laique, Email: talhalaique51@gmail.com Tel:+92-331-0346682
}

\begin{abstract}
Background: BCG is a vaccine obtained by attenuating Mycobacterium bovis. It is a fairly safe vaccine with no associated complications.

Aim: To determine the frequency of accelerated BCG response in BCG vaccinated children.

Study design: Descriptive case series.

Methodology: A total of 124 already BCG vaccinated patients, having age in the range of 6 months to 10 years of either gender were included in the study. Patients with known case of TB and any other systemic disease were excluded. After this, BCG vaccination was given by the researcher himself who noted the in-duration after 72 hrs of BCG vaccination accelerated response of BCG. Chi square test was applied with $\mathrm{P}$-value $<0.05$ as significant. Results: Mean age was 6.02 2.22 years. Out of the 124 patients, 63(50.81\%) were male and 61(49.19\%) were females. Mean duration of previous BCG was $4.75 \pm 2.41$ years. Frequency of accelerated BCG response in BCG vaccinated children was found in $76(61.29 \%)$ patients.

Conclusion: This study concluded that the frequency of accelerated BCG response in BCG vaccinated children was $61.29 \%$. So, we suggested that public awareness programs should be arranged to educate people for compulsory BCG vaccination of their children.

Keywords: Bacillus Calmette-Guerin (BCG) Vaccine, Accelerated BCG Response and Tuberculosis.
\end{abstract}

\section{INTRODUCTION}

Mycobacterium tuberculosis (TB) has already infected about 33\% population at world level. One of the biggest health threats at global level i.e efficacious control of TB has been best treated by a group of chemotherapy and vaccination. ${ }^{1,2}$ Albert Calmette and Camille Guerin were French bacteriologists who firstly developed BCG vaccine from 1908 to $1921 .{ }^{3}$ In newborns with high risk of tuberculosis, soon after birth this vaccine is administered but excluding patients of tuberculosis disease. ${ }^{4,5}$ Administration of BCG vaccine is compulsory in 64 countries while it is recommended by others. ${ }^{6}$ BCG is the only vaccine which is used for protection against tuberculosis and has superior protection against tuberculosis meningitis than pulmonary diseases. Bacille Calmette-Guerin (BCG) vaccine efficacy is very controversial (0 to 60 years), suggesting that a single vaccination can have a long duration of protection ${ }^{1}$.

Immunization programs of BCG have been recently expanded by $\mathrm{WHO}$ at 3 months while in many countries it is either rat birth or before school entry or at adolescence. ${ }^{6}$ For many years, Greece had policy of administering BCG vaccination in school children during age of 11-13 years and they got TB infection index of $3.4 \%$. Moreover, they have recommend BCG vaccination in school children in routine till the risk of TB infection is reduced all over the Greece. ${ }^{7,8}$ Even with recent rare instances of $T B$, this continuous vaccination throughout the country is to avoid instances of missing due to mobility of people i.e. joining army school, seeking employment or moving to colleges in

Received on 27-12-2020

Accepted on 03-01-2021 other cities where occurrence of TB is high ${ }^{9,10}$

However, there is strong controversy regarding efficacy of BCG vaccine. Based on adult and older children studies, protection rate is 0 in India, 14\% in southern USA and $77 \%$ in the Britain ${ }^{9}$. Furthermore, many reported who had earlier recommended to adopt policy of continuous $B C G$ vaccination in routine are now showing concern about quality of vaccine, its mode of transportations and its application technique. ${ }^{6}$ Recent resurgence of TB infection at world level may be associated with widespread HIV and carelessness in TB control programs ${ }^{11}$. However, it has been held by statistical and methodological reappraisals that conflicting data is due to different environmental and biological conditions where these individual studies were conducted besides inadequate statistical power or biases ${ }^{12}$. It was recently reporting by findings of 15 years that BCG offered certain levels of overall protection in areas with high non-specific sensitivity and high infection rates where BCG did not offer any protection against adult forms of military pulmonary tuberculosis ${ }^{6}$.

In a study, accelerated BCG response in BCG vaccinated children was found to be $71 \%^{12}$. As the BCG vaccine is used for diagnostic and therapeutic purpose hence knowing efficacy of BCG vaccine which is very controversial. Purpose of this study was to see the response of BCG vaccine in already BCG vaccine children. Previously very limited literature is present on this topic. Moreover, no local data is available. The results of my study will provide the local stats of the problem and also encourage the healthcare workers and management for proper effective and proper dosage of BCG vaccine in order to achieve its maximum results and thus reduce the morbidity of our population. 
The objective of the study was to determine the frequency of accelerated BCG response in BCG vaccinated children.

\section{METHODOLOGY}

This descriptive case series was conducted at the Department of Pediatric Medicine Unit I, Bahawal Victoria Hospital, Bahawalpur for a period of 6 months with effect 20th October 2018 to 19th April 2019. Sample size of 124 patients was calculated with anticipated proportion of $71.0 \%$ at $95 \%$ confidence internal and precision required $0.08(d)^{13}$. Non-probability, consecutive sampling technique was used. Patients with age between 6 months to 10-years were included from both the genders who had already been BCG vaccinated and were admitted at department of pediatrics for any reason. However, patients with known TB and any other systemic disease were excluded. An informed written consent was taken from all the parents/guardians. Approval from ethical review committee was taken. After this BCG vaccination was given by the researcher himself who noted the in-duration after 72 hours of $B C G$ vaccination accelerated response of $B C G$ was noted as per-operational definition.

Statistical Analysis: For data analysis, SPSS version-21 was used. Quantitative variables i.e. age, weight, area of residence and duration of previous BCG have been presented as mean and standard deviation. The frequency of Accelerated BCG response, gender, area of residence (urban/rural) was calculated. To control effect modifiers, data has been stratified for age, gender, weight, height, duration of previous BCG and area of residence. Chi square test was applied with $\mathrm{P}$-value $<0.05$ as significant.

\section{RESULTS}

Out of the 124 patients, 63(50.81\%) were male and $61(49.19 \%)$ were females. Mean weight of patients was $24.35 \pm 7.80 \mathrm{~kg}$. Various other general parameters were described in table-1.

Table-1: General Parameters Described As Frequency \& Percentage

\begin{tabular}{|c|c|c|c|}
\hline Parameters & Categories & Frequency & \%age \\
\hline \multirow{3}{*}{ Age (years) } & 6 Months- 5 Yrs & 55 & $44.35 \%$ \\
\hline & $6-10$ & 69 & $55.65 \%$ \\
\hline & Mean +SD & \multicolumn{2}{|c|}{$6.02+2.22$} \\
\hline \multirow[b]{2}{*}{ Gender } & Male & 63 & $50.81 \%$ \\
\hline & Female & 61 & $49.19 \%$ \\
\hline \multirow{3}{*}{ Weight (kg) } & $\leq 25$ & 66 & $53.23 \%$ \\
\hline & $>25$ & 58 & $46.77 \%$ \\
\hline & Mean +SD & \multicolumn{2}{|c|}{$24.35+7.80$} \\
\hline \multirow{3}{*}{ Height $(\mathrm{cm})$} & $\leq 125$ & 41 & $33.06 \%$ \\
\hline & $>125$ & 83 & $66.94 \%$ \\
\hline & Mean +SD & \multicolumn{2}{|c|}{$132.11+9.29$} \\
\hline \multirow{3}{*}{$\begin{array}{l}\text { Previous BCG } \\
\text { (years) }\end{array}$} & $\leq 5$ & 60 & $48.39 \%$ \\
\hline & $>5$ & 64 & $51.61 \%$ \\
\hline & Mean +SD & \multicolumn{2}{|c|}{$4.75+2.41$} \\
\hline \multirow[b]{2}{*}{ Place of living } & Rural & 79 & $63.31 \%$ \\
\hline & Urban & 45 & $36.29 \%$ \\
\hline \multirow{2}{*}{$\begin{array}{l}\text { Increased } \\
\text { BCG } \\
\text { response }\end{array}$} & Yes & 76 & 61.29 \\
\hline & No & 48 & 38.71 \\
\hline
\end{tabular}

Frequency of accelerated BCG response in BCG vaccinated children was found in $76(61.29 \%)$ patients as shown by results. Stratification of accelerated BCG response with respect to different parameters was given in table-2.

Table-2: Stratification Of Accelerated BCG Response

\begin{tabular}{|l|l|c|c|c|}
\hline \multicolumn{2}{|l|}{ Description } & \multicolumn{2}{c|}{$\begin{array}{c}\text { Accelerated BCG } \\
\text { Response }\end{array}$} & \multirow{2}{*}{ P-value } \\
\cline { 3 - 4 } \multicolumn{2}{|l|}{} & Yes & No & \\
\hline \multirow{2}{*}{ Gender } & Male & 38 & 25 & \multirow{2}{*}{0.821} \\
\cline { 2 - 4 } & Female & 38 & 25 & \\
\hline \multirow{2}{*}{$\begin{array}{l}\text { Age } \\
\text { (years) }\end{array}$} & 6 months-5 yrs & 29 & 26 & \multirow{2}{*}{0.080} \\
\cline { 2 - 4 } $\begin{array}{l}\text { Weight } \\
\text { (kg) }\end{array}$ & $6-10$ & 47 & 22 & \\
\cline { 2 - 4 } $\begin{array}{l}\text { Height } \\
\text { (cm) }\end{array}$ & $>25$ & 37 & 29 & \multirow{2}{*}{0.202} \\
\cline { 2 - 4 } $\begin{array}{l}\text { Previous } \\
\text { BCG(Yrs) }\end{array}$ & $<125$ & 39 & 19 & \\
\cline { 2 - 4 } & $>5$ & 27 & 14 & \multirow{2}{*}{0.463} \\
\hline \multirow{2}{*}{ Residence } & Rural & 39 & 34 & \\
\cline { 2 - 4 } & Urban & 39 & 23 & \multirow{2}{*}{0.934} \\
\hline
\end{tabular}

${ }^{*}$ Statistically significant

\section{DISCUSSION}

BCG vaccine reduces risks of extra-pulmonary and pulmonary TB about $50 \%$. However against disseminated TB diseases and TB meningitis its efficacy is $78 \%$ and $64 \%$ respectively. ${ }^{1,2}$ BCG vaccine is also little bit effective against non-TB mycobacterial infections and leprosy. Moreover, it is also used for bladder superficial carcinoma ${ }^{3}$.

At site of injection, red in-durated area followed by BCG vaccination is its typical reaction and it may ulcerate subsequently and crust is formed that takes about 6 weeks to fall off leaving behind only a small scare. A normal response after BCG vaccination is axillary lymphadenopathy $(<1 \mathrm{~cm}){ }^{6}$ About $1-10 \%$ adverse reactions have ben associated with BCG vaccine but many instances remained unreported. ${ }^{7,9}$ There is an association between strain of BCG administered and appearance of adverse reaction ${ }^{9}$.

This study was conducted to determine the frequency of accelerated BCG response in BCG vaccinated children. Mean age of the patients was $6.02 \pm 2.22$ years. A similar mean age of $5.99 \pm 2.17,{ }^{13} 6.08 \pm 1.65,{ }^{14} 6.31 \pm 3.17^{15}$ among such patients was reported by some other studies except one study that reported $9.50 \pm 4.19 .{ }^{16}$ Age of most of the patients 69 (55.65\%) was between 6 to 10 years of 1zage. Out of the 124 patients, $63(50.81 \%)$ were male and $61(49.19 \%)$ were female with male to female ratio of 1:1.1. Other studies have also reported similar male to female ratio $1: 1.2,{ }^{13} 1: 1.0,{ }^{14} 1: 1.4^{17}$ except one $1: 0.8 .^{16}$ In my study, frequency of accelerated BCG response in BCG vaccinated children was found in 76(61.29\%) patients. In a study, accelerated BCG response in BCG vaccinated children was found to be $71 \%$ that strengthens results of our study ${ }^{12}$.

In comparison with any other age group, children with age 5-14 years have lower rate of TB. In young children chances to develop disseminated, meningeal or lymphatic TB are very high and in presentation of genitourinary, pleural or peritoneal disease is more likely. In comparison with women, TB rate of TB infection is consistently high in 
men during adulthood; the male-to-female ratio is approximately $2: 1 .{ }^{15}$ Efficacy of BCG is different in different situations as a Columbian study showed efficacy of vaccine $35 \%{ }^{16}$ while another study showed protective effect of BCG in pulmonary TB from $0-80 \% .{ }^{17}$ Two centers from UK have presented conflicting results where $25 \%$ had no visible scare ${ }^{11}$ while $45-46 \%$ of vaccinated children were Mantoux positive ${ }^{12}$ However, in a study conducted at third center on Asian neonates, 98\% were tuberculin positive after BCG vaccination, ${ }^{13}$ and similar results $95 \%$ were shown by another Asian study. ${ }^{14}$ For vole bacillus and BCG vaccines, protective efficacy after fifteen years was $80.8 \%(99 \% \mathrm{Cl}$ $68 \%$ to $91 \%)$ and $78.4 \%$ (99\% Cl $69 \%$ to $86 \%)$ respectively. Only ten cases pulmonary TB and TB meningitis were reported and all belonged to nonvaccinated patients. ${ }^{15} \mathrm{~A}$ combined risk of TB was shown by meta-analysis of prospective trials $0.49(95 \% \mathrm{Cl} 0.34$ to $0.70) .^{16}$

Limitation: Our study had several limitations like financial constraints, time restrictions, small sample number and we could not follow subjects for a longer period of time which is an important aspect of management and should be considered in future studies.

\section{CONCLUSION}

It was concluded that the frequency of accelerated BCG response in BCG vaccinated children was $61.29 \%$. So, we suggest that public awareness programs should be arranged to educate people for compulsory BCG vaccination of their children at birth in order to prevent pulmonary tuberculosis as well as its complications.

Author contribution: MI: Overall supervision, write up and literature review. SUM: Statistics application analysis literature review, help in write up. TL: Literature review help in write-up.

Acknowledgement: I am thankful to Allah and all my colleagues for their help.

Running head: Analysis of accelerated BCG vaccine among children.

Conflict of Interest: None to declare

Financial Disclosure: None

\section{REFERENCES}

1. Birk NM, Nissen TN, Kjærgaard J, Hartling HJ, Thøstesen $\mathrm{LM}$, Kofoed PE, et al. Effects of Bacillus Calmette-Guérin (BCG) vaccination at birth on $T$ and $B$ lymphocyte subsets: Results from a clinical randomized trial. Sci Rep 2017;7(1):12. doi: 10.1038/s41598-017-11601-6

2. Sellami K, Amouri M, Kmiha S, Bahloul E, Aloulou H, Sfaihi L, et al. Adverse reactions due to the bacillus Calmette-Guerin vaccine: Twenty Tunisian cases. Ind $\mathrm{J}$ Dermatol 2018;63(1):62. doi: 10.4103/ijd.IJD_327_17

3. Cernuschi T, Malvolti S, Nickels E, Friede M. Bacillus Calmette-Guérin (BCG) vaccine: a global assessment of demand and supply balance. Vaccine 2018;36(4):498-506. doi: 10.1016/j.vaccine.2017.12.010

4. Siddiqui KF, Amir M, Khan N, Rama Krishna G, Sheikh JA, Rajagopal K, et al. Prime boost vaccination strategy with bacillus Calmette-Guérin (BCG) and liposomized alphacrystalline protein 1 reinvigorates BCG potency. Clin Immunol 2015;181(2):286-96. doi: 10.1111/cei.12634

5. Nieuwenhuizen NE, Kaufmann SH. Next-generation vaccines based on bacille Calmette-Guérin. Front Immunol 2018:9:121. doi: 10.3389/fimmu.2018.00121

6. Kjærgaard J, Stensballe LG, Birk NM, Nissen TN, Thøstesen LM, Pihl GT, et al. Bacillus Calmette-Guérin vaccination at birth: Effects on infant growth. A randomized clinical trial. Dan Med J 2016;100:49-54.

7. Moliva JI, Turner J, Torrelles JB. Immune responses to bacillus Calmette-Guerin vaccination: why do they fail to protect against mycobacterium tuberculosis?. Front Immunol 2017;8:407. doi: 10.1016/j.jctube.2018.02.001

8. Oberoi S, Amarjit S, Avneet R, Neha C, Patnaik S. Positive impact of rescheduling Bacillus Calmette-Guérin vaccination on vaccinations at birth. J Fam Med 2017;24(1):13. doi: $10.4103 / 2230-8229.197176$

9. Negrete-Esqueda L, Vargas-Origel A. Response to Bacillus Calmette-Guerin vaccine in full-term and preterm infants. Am J Perinatol 2007;24(03):183-9. doi : 10.5812/pedinfect.37490

10. Hawn TR, Day TA, Scriba TJ, Hatherill M, Hanekom WA, Evans TG, et al. Tuberculosis vaccines and prevention of infection. Am Soc Microbiol 2014;78(4):650-71. doi: 10.1128/CMR.00100-19

11. Nayak S, Acharjya B. Mantoux test and its interpretation. Ind Dermatol J 2012;3(1):2. doi: 10.4103/2229-5178.93479

12. Anjum R, Qayum S, Rashid A. Evaluation of BCG test in diagnosis of tuberculosis in BCG vaccinated children and its comparison with Mantoux test. Int $\mathrm{J}$ Contemp Pediatr 2016;3(4):1339. doi: 10.18203/2349-3291.ijcp20163673

13. Lancella L, Vecchio AL, Chiappini E, Tadolini M, Cirillo D, Tortoli E, et al. How to manage children who have come into contact with patients affected by tuberculosis. J Fam Med 2015;1:1-2. doi: 10.4103/2230-8229.197176

14. McShane $\mathrm{H}$. Tuberculosis vaccines: beyond bacille Calmette-Guérin. Philos Trans $\mathrm{R}$ Soc Lond Biol 2011;366(1579):2782-9. doi: 10.1098/rstb.2011.0097

15. Barreto ML, Pereira SM, Ferreira AA. BCG vaccine: efficacy and indications for vaccination and revaccination. J Pediatr 2006;82(3):45-54.

16. Monajemzadeh $M$, Shahsiah $R$, Zarei A, Alamooti AA, Mahjoub F, Mamishi S, et al. Frequency of bacille CalmetteGuerin (BCG) and Mycobacterium tuberculosis in tissue biopsy specimens of children vaccinated with BCG. Am J Clin Pathol doi.org/10.1309/AJCPXLZPRHX9LOYG

17. Teo SS, Smeulders N, Shingadia DV. BCG vaccineassociated suppurative lymphadenitis. Vaccine 2005;23(20):2676-9. doi: 10.1016/j.vaccine.2004.07.052. 